\title{
The parthenocarpic gene Pat- $k$ is generated by a natural mutation of SIAGL6 affecting fruit development in tomato (Solanum lycopersicum L.)
}

Rihito Takisawa ${ }^{1 *}$ (D), Tetsuya Nakazaki ${ }^{1}$, Tsukasa Nunome ${ }^{2}$, Hiroyuki Fukuoka ${ }^{3}$, Keiko Kataoka $^{4}$, Hiroki Saito ${ }^{1,5}$, Tsuyoshi Habu ${ }^{4}$ and Akira Kitajima'

\begin{abstract}
Background: Parthenocarpy is a desired trait in tomato because it can overcome problems with fruit setting under unfavorable environmental conditions. A parthenocarpic tomato cultivar, 'MPK-1', with a parthenocarpic gene, Pat-k, exhibits stable parthenocarpy that produces few seeds. Because 'MPK-1' produces few seeds, seedlings are propagated inefficiently via cuttings. It was reported that Pat-k is located on chromosome 1. However, the gene had not been isolated and the relationship between the parthenocarpy and low seed set in 'MPK-1' remained unclear. In this study, we isolated Pat-k to clarify the relationship between parthenocarpy and low seed set in 'MPK-1'.

Results: Using quantitative trait locus (QTL) analysis for parthenocarpy and seed production, we detected a major QTL for each trait on nearly the same region of the Pat-k locus on chromosome 1. To isolate Pat-k, we performed fine mapping using an $\mathrm{F}_{4}$ population following the cross between a non-parthenocarpic cultivar, 'Micro-Tom' and 'MPK-1'. The results showed that Pat-k was located in the $529 \mathrm{~kb}$ interval between two markers, where 60 genes exist. By using data from a whole genome re-sequencing and genome sequence analysis of 'MPK-1', we could identify that the SIAGAMOUS-LIKE 6 (SIAGL6) gene of 'MPK-1' was mutated by a retrotransposon insertion. The transcript level of SIAGL6 was significantly lower in ovaries of 'MPK- 1 ' than a non-parthenocarpic cultivar. From these results, we could conclude that Pat-k is SIAGL6, and its downregulation in 'MPK-1' causes parthenocarpy and low seed set. In addition, we observed abnormal micropyles only in plants homozygous for the 'MPK-1' allele at the Pat-k/SIAGL6 locus. This result suggests that Pat-k/ SIAGL6 is also related to ovule formation and that the low seed set in 'MPK-1' is likely caused by abnormal ovule formation through down-regulation of Pat-k/SIAGL6.
\end{abstract}

Conclusions: Pat-k is identical to SIAGL6, and its down-regulation causes parthenocarpy and low seed set in 'MPK-1'. Moreover, down-regulation of Pat-k/SIAGL6 could cause abnormal ovule formation, leading to a reduction in the number of seeds.

Keywords: Parthenocarpy, Tomato, Pat-k, QTL, Number of seeds, Ovule

\footnotetext{
* Correspondence: takisawa@kais.kyoto-u.ac.jp

${ }^{1}$ Graduate School of Agriculture, Kyoto University, Kizugawa 619-0218, Japan

Full list of author information is available at the end of the article
}

(c) The Author(s). 2018 Open Access This article is distributed under the terms of the Creative Commons Attribution 4.0 International License (http://creativecommons.org/licenses/by/4.0/), which permits unrestricted use, distribution, and reproduction in any medium, provided you give appropriate credit to the original author(s) and the source, provide a link to the Creative Commons license, and indicate if changes were made. The Creative Commons Public Domain Dedication waiver (http://creativecommons.org/publicdomain/zero/1.0/) applies to the data made available in this article, unless otherwise stated. 


\section{Background}

Parthenocarpy is defined as fruit set and growth without fertilization or other stimulation. In tomato, parthenocarpy is a desirable trait that reduces financial and labor costs of fruit set [1]. In addition, it can increase yield under unfavorable conditions: low or high temperatures, low and high humidity, and low light intensity, all of which inhibit fruit set and growth by impeding the reproductive process $[2,3]$.

Some natural sources for parthenocarpy in tomato include 'Soressi' and 'Montfavet191' (pat), 'Severianin' (pat-2), 'RP75/59' (pat3/pat4), 'IL5-1' (pat4.1/pat5.1), 'IVT-line1' (pat4.2/pat9.1), and 'MPK-1' (Pat-k) $[1,4,5]$. Of these genes, only the pat-2 gene which is located on chromosome 4, has been isolated thus far; it has been determined to encode a zinc-finger homeodomain protein [6].

The parthenocarpic tomato cultivar 'MPK-1' exhibits stable parthenocarpy. Hosokawa [7] reported that 'MPK-1' was derived from a cross between a non-parthenocarpic cultivar and a variant from a self-fertilized descendant of 'Severianin', which exhibits strong parthenocarpy. It is thought that the parthenocarpic trait of 'MPK-1' is derived from pat-2 because 'Severianin' is its only parthenocarpic parent [8]. However, recently we found that the parthenocarpy of 'MPK-1' is controlled by a novel parthenocarpic gene, Pat- $k$ which is located on chromosome 1 [1].

'MPK-1' is commercially cultivated in Kyoto Japan, under the name 'Kyo-temari'. The seedlings of 'MPK-1' must be vegetatively propagated from cuttings because seed production is extremely inhibited in 'MPK-1' [9]. Takisawa [8] observed that many ovules of 'MPK-1' have an abnormal micropyle, which might cause the inhibition of seed formation in 'MPK-1'. In addition, 'MPK-1' has abnormally-fused sepals [1]. One of the natural parthenocarpy mutants, the pat mutant, exhibits partial aberrations of the stamens and ovules [10], indicating that pat may result from the mutation of a putative gene with homeotic functions. In addition, down-regulation or mutation in some MADS-box genes in tomato (TM29, TAP3, TM8, or SlAGL11) not only causes homeotic conversion in flowers but also parthenocarpic fruit development [11-14]. Therefore, it would be reasonable to assume that Pat-k not only causes parthenocarpy but also possesses a homeotic function, which might cause the inhibition of seed formation in 'MPK-1'.

In this study, we performed QTL analysis, fine mapping, and map-based cloning to isolate Pat-k and to elucidate the relationship between parthenocarpy and the inhibition of seed formation in 'MPK-1'. In addition, we also observed ovule structure of plants that were homozygous for 'Micro-Tom' or 'MPK-1' allele at the Pat-k locus to clarify the effect of Pat-k on ovule formation.

\section{Methods}

\section{Plant materials and plant growth condition}

We developed an $F_{2}$ population $(n=89)$ for QTL analysis following the cross between a non-parthenocarpic tomato cultivar, 'Micro-Tom', (Tomato Growers Supply Company, Florida, USA) and a parthenocarpic cultivar, 'MPK-1', following procedures of Takisawa [1]. For the progeny test, an $F_{3}$ population $(n=42)$ was developed from a single $\mathrm{F}_{2}$ plant that was heterozygous at the Pat- $k$ locus. We sowed seeds of the $F_{3}$ population in April 2015 and grew them in the greenhouse at the Takatsuki Experimental Farm of Kyoto University, located in Takatsuki, Japan (Takatsuki Farm, 3451'N, 135 37'E) in the spring of 2015. To conduct fine mapping of Pat- $k$, we developed an $\mathrm{F}_{4}$ population $(n=507)$ from three $\mathrm{F}_{3}$ plants that were heterozygous at the Pat-k locus. Seeds of the $F_{4}$ population were sown in September 2015, and each $F_{4}$ seedling was subjected to recombinant screening to seek recombinants in the corresponding area of the Pat-k locus. Selected $F_{4}$ recombinants were grown in the greenhouse of the Takatsuki Farm in the autumn of 2015.

For expression analysis, we used two tomato cultivars, a non-parthenocarpic tomato cultivar, 'Louis 60' (TAKII SEED, Kyoto, Japan) and 'MPK-1'. The plants of the two cultivars were grown in a greenhouse at the Takatsuki Farm in the autumn of 2015 for sampling ovaries and at the Kizu Experimental Farm of Kyoto University at Kizugawa, Japan (Kizu Farm, 34 $73^{\prime} \mathrm{N}, 135^{\circ} 84^{\prime} \mathrm{E}$ ) in the spring of 2016 for sampling buds.

For histological analysis of ovules, an $\mathrm{F}_{3}$ population was developed from two $F_{2}$ plants that were heterozygous for the Pat-k locus. Seeds of the $F_{3}$ population were sown in April 2017. We grew them in the greenhouse at the Kizu Farm in the spring of 2017. In addition, 'Micro-Tom' and 'MPK-1' were grown in a greenhouse at the Takatsuki Farm in the autumn of 2013.

\section{The evaluation of parthenocarpy and seed production}

We obtained phenotype data for the $F_{2}, F_{3}$, and $F_{4}$ populations using the following procedure. We emasculated five flowers within one or two flower clusters at one day before anthesis (-1 DAA). Ten flowers within more than two flower clusters were pollinated at anthesis (0 DAA). After weighing the emasculated and pollinated fruits, we checked for the absence of seeds in the emasculated fruits and counted the number of seeds in the pollinated fruits. Parthenocarpy level (PL) (i.e., percentage of average weight of emasculated fruits to that of pollinated fruits) was used to evaluate the degree of parthenocarpy. PL of any plant with emasculated ovaries that dropped (or did not grow) was defined as $0 \%$. All PL data were arcsine transformed prior to QTL analysis in order to improve the normality of the distribution. 


\section{DNA extraction}

We used frozen, young leaves for extracting DNA. The DNA for our single nucleotide polymorphism (SNP) analysis, and for whole genome re-sequencing of 'MPK1, was extracted using a DNeasy Plant Mini Kit (Qiagen $\mathrm{GmbH}$, Hilden, Germany). For the other investigations, we extracted DNA with a Nucleon PhytoPure kit (GE Healthcare, Buckinghamshire, UK), according to the manufacturer's instructions.

\section{SNP analysis and linkage map construction}

We conducted SNP analysis to detect SNP genotypes of the 89 plants of the $\mathrm{F}_{2}$ population by using the Axiom ${ }^{\circ}$ tomato Genotyping Array (Takara Bio, Shiga, Japan), which contains 52,425 SNPs [15]. We selected SNPs that satisfied following conditions for construction of a linkage map: (1) homozygous in 'Micro-Tom' and 'MPK-1', (2) polymorphic between 'Micro-Tom' and 'MPK-1', and (3) less than 10\% missing data. The linkage groups were formed according to the information of the location of the SNPs in the tomato genome (SL2.40). A genetic map was constructed using JoinMap4.1 mapping software with default settings of a maximum-likelihood mapping algorithm.

\section{QTL analysis}

QTL analyses were performed with the linkage map and phenotype data from the $F_{2}$ population: arcsine transformed PL and number of seeds. Composite interval mapping was performed with Windows QTL Cartographer software v.2.5 [16]. The logarithm of odds (LOD) thresholds of PL and number of seeds were determined by one thousand permutation tests at the $5 \%$ level for each trait. In order to evaluate the effect of the detected QTLs, we classified the $F_{2}$ population according to the genotypes of the nearest markers linked to the QTLs. Multiple comparisons were conducted with the Tukey-Kramer test.

\section{Whole genome re-sequencing of 'MPK-1'}

Whole genome re-sequencing of 'MPK-1' was performed by the Macrogen Japan service (Macrogen Japan, Tokyo, Japan). The 100 bp pair-end reads were generated using the HiSeq2000 system (Illumina, California, USA). The quality of these data was evaluated based on total reads and the content of GC, AT, Q20, and Q30 (Additional file 1: Table S1). The obtained data were aligned to the tomato reference genome sequence (SL2.40) using BWA software in the DDBJ Read Annotation Pipeline [17]. SNPs between the tomato reference genome ('Heinz 1706') and 'MPK-1' were identified with SAMtools software. Integrative Genomics Viewer (IGV) free software was used to view the sequences [18].

\section{Fine mapping of Pat-k}

We selected $\mathrm{F}_{4}$ recombinants using two DNA markers, Affx-93,173,536 and TGS0486, which flanked the Pat-k locus in this study. Affx-93,173,536 was a cleaved amplified polymorphic sequence (CAPS) marker, which was designed using SNP data between 'Micro-Tom' and 'MPK-1' (Additional file 1: Table S2). TGS0486 was an SSR marker, which was linked to Pat-k [1]. In addition, we acquired SNPs between 'Micro-Tom' and 'MPK-1' by comparing two SNP data sets: (1) SNPs between 'Heinz 1706' and 'Micro-Tom' genome from TOMATOMICS [19] and (2) SNPs between 'Heinz 1706' and the 'MPK-1' genome obtained in this study. We selected four SNPs to increase the map resolution near the Pat- $k$ locus. We also developed CAPS markers to detect genotypes of the $\mathrm{F}_{4}$ recombinants for two SNPs (SNP6 and SNP13). For the other two SNPs (SNP17 and SNP19), we applied the direct sequencing method (Additional file 1: Table S2).

\section{Genomic sequence analysis of Solyc01g093960 in 'MPK-1'}

We determined the genome sequence corresponding to the open reading frame of Solyc01g093960 in the International Tomato Annotation Group, release 2.40, using whole genome re-sequencing data of 'MPK-1'. An insertion sequence, which was found at the first intron of Solyc01g093960, was amplified using a set of primers: forward primer sequence (093960_fwd) (5'-ACAGTTG ATGTGTGCCTTTGTCTCTCAACAA-3') and reverse primer sequence (093960_rev) (5'-GAGAGAGTGAAAGA CAGTGAGGTCA-3'). PCR reactions were performed in a total volume of $50 \mu \mathrm{L}$ PrimeSTAR ${ }^{\circ}$ GXL DNA Polymerase (Takara Bio, shiga, Japan), according to the manufacturer's instructions. Amplification was performed under the following conditions: $94{ }^{\circ} \mathrm{C}$ for $5 \mathrm{~min}, 35$ cycles of $98{ }^{\circ} \mathrm{C}$ for $10 \mathrm{~s}$, and $68{ }^{\circ} \mathrm{C}$ for $8 \mathrm{~min}$; a final extension step was conducted at $72{ }^{\circ} \mathrm{C}$ for $7 \mathrm{~min}$. The PCR products were run on $1.0 \%$ agarose gels and stained with Midori Green Advance (NIPPON Genetics,Tokyo, Japan) to confirm their amplification, after which they were purified with FastGene Gel/PCR Extraction Kit (NIPPON Genetics, Tokyo, Japan). Primer walking of the insertion fragment was performed by the FASMAC (Fasmac, Kanagawa, Japan) and Hokkaido System science (Hokkaido System Science, Hokkaido, Japan) sequencing service using 15 primers (Additional file 1: Table S3).

\section{Quantitative RT-PCR analysis of Solyc01g093960}

We collected buds of three sizes $(6,8$, and $10 \mathrm{~mm})$ and ovaries at $-1,0,1,3,5$, and 7 days after anthesis (DAA). Both unpollinated and pollinated ovaries were prepared by emasculation at $-1 \mathrm{DAA}$ and pollination at $0 \mathrm{DAA}$, respectively. The collected buds and ovaries were frozen in liquid $\mathrm{N}_{2}$ and stored at $-80{ }^{\circ} \mathrm{C}$ in a freezer until ready to extract RNA. Total RNA was extracted using Sepasol ${ }^{\circ}$ - 
RNA I Super G (NACALAI TESQUE, Kyoto, Japan), according to the manufacturer's instructions. cDNA was synthesized using ReverTra Ace qPCR RT Kit (Toyobo, Tokyo, Japan). Quantitative RT-PCR was performed with the LightCycler 480 System (Roche Applied Science, Mannheim, Germany) using THUNDERBIRD ${ }^{\circ}$ SYBR qPCR Mix (Toyobo, Tokyo, Japan). The primers used for expression analysis of Solyc01g093960 were designed using Primer 3 plus [20] (Additional file 1: Table S4). Transcript levels for the genes were normalized with the expression of the housekeeping gene, Sl-Actin [21] (Additional file 1: Table S4). Amplification was performed under the following conditions: $95^{\circ} \mathrm{C}$ for $1 \mathrm{~min}, 45$ cycles of $95^{\circ} \mathrm{C}$ for $10 \mathrm{~s}$, $60{ }^{\circ} \mathrm{C}$ for $25 \mathrm{~s}$, and $72{ }^{\circ} \mathrm{C}$ for $25 \mathrm{~s}$; a final step at $40{ }^{\circ} \mathrm{C}$ for $30 \mathrm{~s}$ completed the amplification procedure. Three biological replicates were performed.

\section{The observation of ovules with light microscopy}

At 0 DAA, two ovaries were sampled in each of the three $F_{3}$ plants that were homozygous for the 'MPK-1' allele and the three $F_{3}$ plants that were homozygous for the 'Micro-Tom' allele at the Pat- $k$ locus. In all the $F_{3}$ plants we used, the genotype at the nearest marker of two QTLs for number of seeds on chromosome 2 and 4 were 'MPK-1' homozygous.

Ovaries were fixed with formalin-acetic acid-alcohol: 50\% ethanol, glacial acetic acid, and formalin at the ratio of 18:1: $1(\mathrm{v} / \mathrm{v} / \mathrm{v})$. After one night, the ovaries were washed with running tap water and then dehydrated with a series of ethanol treatments: $30 \%, 70 \%, 90 \%, 99 \%$, and $100 \%$ ethanol $(v / v)$. After substituting ethanol with Technovit 7100 resin (Heraeus Kulzer, Wehrheim, Germany), the samples were embedded in resin and coagulated in a mold. Transverse sections $(2 \mu \mathrm{m}$ thick) were prepared with a rotary microtome and then stained with toluidine blue $\mathrm{O}$ to observe the morphology of ovules with light microscopy. Based on this observation, ovules were separated into the following two types: normal ovule (with micropyle that was properly closed) and abnormal ovule (with micropyle that had a cavity). We observed 10-12 ovules in each plant and evaluated ovule aberrancy as the percentage of the number of abnormal ovules to all observed ovules.

\section{Results}

\section{Distribution of the PL and number of seeds}

The PL of 'Micro-Tom' was 0\% because its emasculated ovaries did not grow after anthesis. In contrast, emasculated ovaries of 'MPK-1' grew to the almost the same size as pollinated fruits (its PL was 104\%). The mean number of seeds produced by 'Micro-Tom' was 28.9, whereas 'MPK-1' produced no seeds. The $F_{2}$ population showed a continuous distribution in PL values (ranging from $0 \%$ to $98.2 \%$ ), whereas mean number of seeds ranged from 0 to 141.5 (Fig. 1).

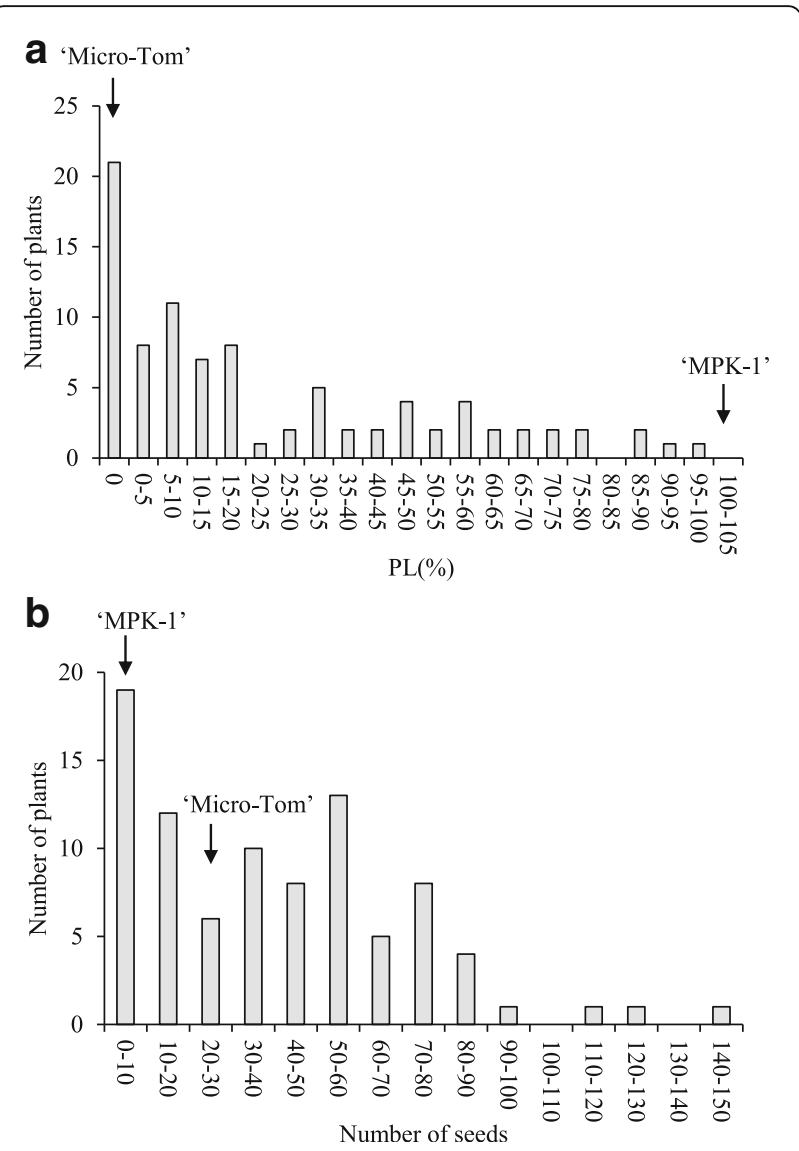

Fig. 1 Frequency distribution of $P L$ and number of seeds in the $F_{2}$ population $(n=89)$. a PL, $\mathbf{b}$ number of seeds

\section{Linkage map construction}

Of the 52,425 SNPs in the genotyping array, 4238 SNPs fulfilled our requirements. The redundant markers detecting no recombination in the $F_{2}$ population were removed because they could not provide any additional information. The selected 1431 SNPs were applied to the construction of our linkage map (Additional file 1: Table S5). The linkage map covered a total of $2082 \mathrm{cM}$ and contained 12 chromosomes. The average marker interval of this map was $1.5 \mathrm{cM}$.

\section{QTL analysis for PL}

In the QTL analysis for PL, we detected only one QTL, qpat1.1 at $224.9 \mathrm{cM}$ of chromosome $1\left(\mathrm{LOD}=19.4, \mathrm{R}^{2}\right.$ $=70.8)($ Fig. 2a, Table 1). The additive effects of qpat1.1 were positive, indicating that the allele of 'MPK-1' increased PL. Mean PL was $12.5 \%$ for plants homozygous for the 'Micro-Tom' allele at the nearest marker to qpat1.1 (Affx-93,180,219), whereas the PL was $55.7 \%$ for plants homozygous for the 'MPK-1' allele (Table 2). There was a significant difference between them at the $5 \%$ level. 


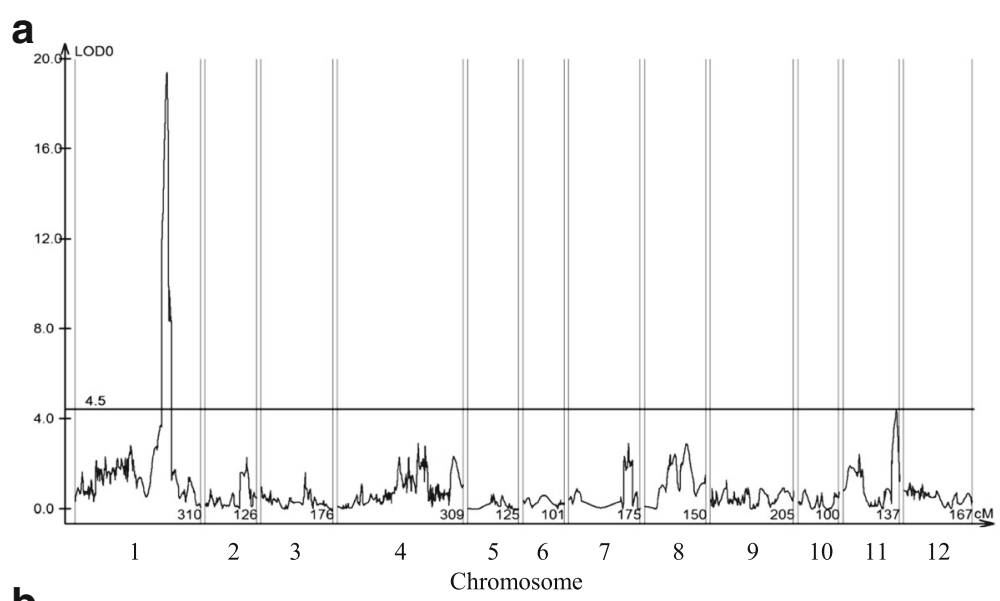

b

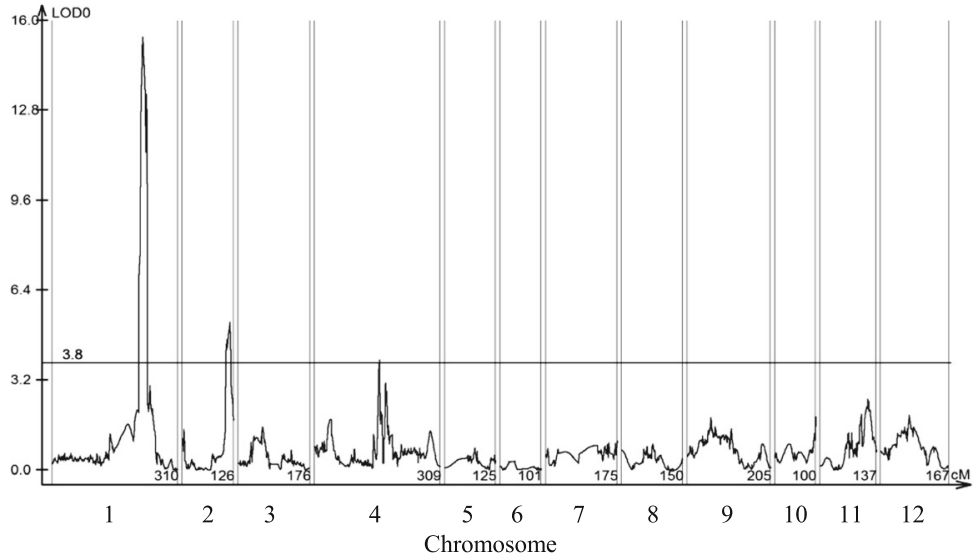

Fig. 2 Lod score distribution in the QTL analyses in the $F_{2}$ population of 'Micro-Tom' and 'MPK-1'. a QTLS of PL after arcsine transformation, b QTLs of number of seeds

To confirm the effect of qpat1.1, we developed an $\mathrm{F}_{3}$ population from a single $F_{2}$ plant with a heterozygous allele for Affx-93,180,219. The mean PL of plants homozygous for the 'MPK-1' allele at the Affx-93,180,219 was significantly higher than that of plants homozygous for the 'Micro-Tom' allele in the $F_{3}$ population (Table 2). Takisawa [1] reported that parthenocarpy in 'MPK-1' is controlled by the parthenocarpic gene, Pat-k, which is linked to the SSR marker, TGS0486 (positioned at $77847211-77847468$ on chromosome 1 in SL2.40). The physical distance between TGS0486 and Affx-93,180,219 was only $234 \mathrm{~kb}$ (Fig. 3b). This result strongly suggested that qpat1.1 is identical to Pat-k. Therefore, we hereafter refer to qpat1.1 as Pat- $k$. In addition, we genotyped two markers (Affx-93,173,536 and TGS0486) in nine $F_{3}$ plants that had the high PL scores and were homozygous for the 'MPK-1' allele at the Affx-93,180,219. As a result, we found that three of the nine plants were heterozygous at Affx-93173536 and homozygous for the 'MPK-1' allele at TGS0486. In addition, one plant was heterozygous at TGS0486 and homozygous for the 'MPK-1' allele at Affx-93173536. Therefore, we could

Table 1 QTLs for PL after arcsine transformation and number of seeds detected in the $F_{2}$ population

\begin{tabular}{|c|c|c|c|c|c|c|c|c|}
\hline Trait & Chromosome & Region of QTL & Nearest marker & Position & LOD & $\begin{array}{l}\text { Additive } \\
\text { effect }\end{array}$ & $\begin{array}{l}\text { Dominant } \\
\text { effect }\end{array}$ & $\mathrm{R}^{2 \mathrm{e}}$ \\
\hline$\overline{\mathrm{PL}}$ & Chr1 & Affx-93,162,137-Affx-93,170,983 & Affx-93,180,219 & 224.9 & 19.4 & 0.4 & -0.3 & 70.8 \\
\hline \multirow[t]{3}{*}{ Number of seeds } & Chr1 & Affx-93,162,137-Affx-107,980,374 & Affx-93,153,041 & 223.2 & 15.4 & -32.3 & 19.2 & 61.9 \\
\hline & Chr2 & Affx-108,001,187-Affx-107,991,951 & Affx-108,004,902 & 115.7 & 5.3 & 8.1 & 11.9 & 3.4 \\
\hline & Chr4 & Affx-107,974,589 & Affx-107,974,589 & 157.9 & 3.9 & 31.1 & -0.1 & 9.8 \\
\hline
\end{tabular}


Table 2 Average PL of each genotypes for qpat1.1 in the $F_{2}$ and $F_{3}$ populations

\begin{tabular}{llllll}
\hline Population & $\begin{array}{l}\text { apat1.1 } \\
\text { (Affx- } \\
93,180,219)\end{array}$ & PL (\%) & & $n^{\mathrm{d}}$ \\
\cline { 3 - 4 } $\mathrm{F}_{2}$ & $\mathrm{M}^{\mathrm{b}}$ & 12.5 & 3.4 & $\mathrm{a}^{\mathrm{a}}$ & 25 \\
& $\mathrm{H}$ & 11.3 & 2.1 & $\mathrm{a}$ & 39 \\
& $\mathrm{~K}$ & 55.7 & 5.2 & $\mathrm{~b}$ & 25 \\
$\mathrm{~F}_{3}$ & $\mathrm{M}$ & 15.5 & 8.8 & $\mathrm{a}$ & 13 \\
& $\mathrm{H}$ & 17.3 & 11.2 & $\mathrm{a}$ & 20 \\
& $\mathrm{~K}$ & 91.2 & 17.4 & $\mathrm{~b}$ & 9 \\
\hline
\end{tabular}

${ }^{a}$ Values followed by the same letter are not significantly different at $P<0.05$ by the Tukey-Kramer test

${ }^{\mathrm{b}}$ Genotypes of the nearest marker. $\mathrm{M}=$ 'Micro-Tom' homozygous, $\mathrm{H}=$

Heterozygous, $\mathrm{K}=$ 'MPK-1' homozygous

'SE: standard error

${ }^{d} n$ : number of plants for each genotype

narrow the chromosome region assumed for the Pat- $k$ locus to be located between Affx-93,173,536 and TGS0486 (Fig. 3b).

\section{QTL analysis for seed production}

Three QTLs for number of seeds were detected on chromosomes 1, 2, and 4, which were designated as qsn1.1, $q s n 2.1$, and $q s n 4.1$, respectively (Fig. 2b, Table 1). The additive effects of $q s n 1.1$ were negative, whereas those of $q s n 2.1$ and qsn4.1 were positive, indicating that the allele for reducing seed production was the 'MPK-1' allele on qsn1.1 and the 'Micro-Tom' allele on qsn2.1 and qsn4.1. The QTL, qsn1.1 was detected at $223.2 \mathrm{cM}$ of chromosome 1 (LOD $\left.15.4, \mathrm{R}^{2}=61.9\right)$, whereas $q s n 2.1$ was detected at $115.7 \mathrm{cM}$

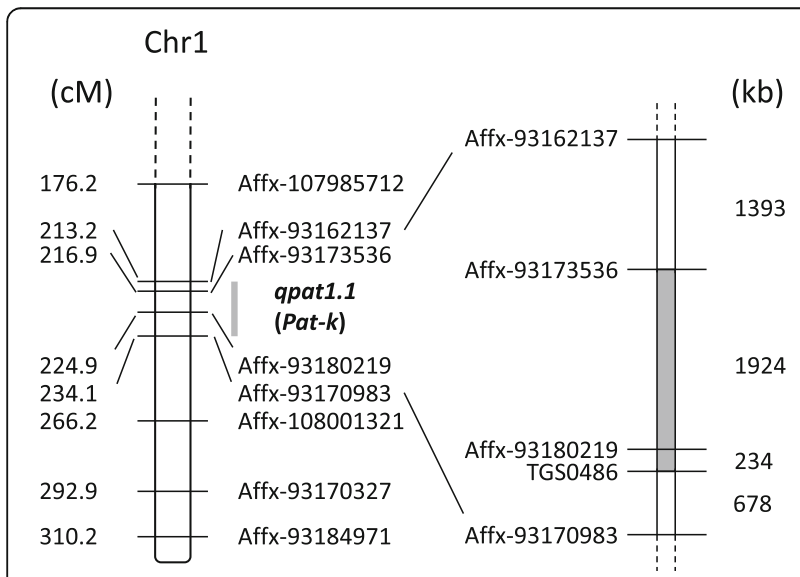

Fig. 3 Genetic and physical map of the chromosome region at the Pat-k locus. Genetic map of the Pat-k locus (left side). Position of the markers are indicated in $\mathrm{CM}$. The gray bar represents the position of the qpat1.1 (Pat-k) locus suggested by QTL analysis in this experiment. Physical map of the Pat-k locus (right side), which was delimited to the region between Affx-93,173,536 and TGS0486 using the data of the $F_{3}$ population. The gray region represents the Pat-k locus, which was narrowed. Distance of the markers are indicated in $\mathrm{kb}$
Table 3 Average number of seeds of each genotype for qsn1.1, qsn2.1, and qsn4.1 in the $F_{2}$ population

\begin{tabular}{|c|c|c|c|c|c|}
\hline \multirow[t]{2}{*}{ Locus } & \multirow[t]{2}{*}{ Genotype } & \multicolumn{3}{|c|}{ seed number } & \multirow[t]{2}{*}{$\mathrm{n}^{\mathrm{d}}$} \\
\hline & & mean & $\mathrm{SE}^{\mathrm{C}}$ & & \\
\hline \multirow[t]{3}{*}{ qsn 1.1} & $M^{b}$ & 55.1 & 4.1 & $a^{a}$ & 27 \\
\hline & $\mathrm{H}$ & 52.9 & 4.9 & $\mathrm{a}$ & 36 \\
\hline & K & 8.2 & 1.4 & $b$ & 26 \\
\hline \multirow[t]{3}{*}{ qsn2.1 } & $M$ & 30.3 & 4.1 & a & 24 \\
\hline & $\mathrm{H}$ & 44.5 & 4.8 & a & 42 \\
\hline & K & 43.7 & 7.7 & a & 23 \\
\hline \multirow[t]{3}{*}{ qsn4.1 } & $M$ & 34.2 & 5.3 & a & 19 \\
\hline & $\mathrm{H}$ & 34.9 & 4.4 & a & 40 \\
\hline & K & 52.3 & 8.0 & $a$ & 23 \\
\hline
\end{tabular}

Values followed by the same letter are not significantly different at $P<0.05$ using the Tukey-Kramer test

${ }^{\mathrm{b}}$ Genotypes of the nearest marker. $\mathrm{M}=$ 'Micro-Tom' homozygous, $\mathrm{H}=$

Heterozygous, $\mathrm{K}=$ 'MPK-1' homozygous

'SE: standard error

${ }^{d} n$ : number of plants for each genotype

of chromosome 2 (LOD 5.3, $\mathrm{R}^{2}=3.4$ ) and qsn4.1 was detected at $157.9 \mathrm{cM}$ of chromosome 4 (LOD 3.9, $\mathrm{R}^{2}=9.8$ ) (Table 1). $\mathrm{F}_{2}$ plants homozygous for the 'MPK-1' allele at the nearest marker to qsn1.1 (Affx-93,153,041) had significantly fewer seeds than plants homozygous for the 'Micro-Tom' allele (Table 3). In contrast, plants homozygous for the 'Micro-Tom' allele at the nearest marker to qsn2.1 (Affx-108,004,902) and qsn4.1 (Affx$107,974,589)$ had fewer seeds than plants homozygous for the 'MPK-1' allele; however, they were not statistically significant.

Whole genome re-sequencing and fine mapping of Pat-k We performed whole genome re-sequencing of 'MPK-1' to isolate Pat-k. We obtained information on SNPs between 'Heinz 1706' and 'MPK-1' using our re-sequencing data. In addition, SNP data between 'Heinz 1706' and 'Micro-Tom' genome were obtained from TOMATOMICS. By comparing these two data sources, we acquired the polymorphic SNPs between 'Micro-Tom' and 'MPK-1'. We found 58 SNPs in the region between Affx-93,173,536 and TGS0486 between 'Micro-Tom' and 'MPK-1' (Additional file 1: Table S6). Using these SNP data, we developed two CAPS markers (SNP17 and SNP19). We then performed fine mapping with the $\mathrm{F}_{4}$ population, which was from three $\mathrm{F}_{3}$ plants heterozygous for the two markers, Affx-93,173,536 and TGS0486 to narrow the interval of the Pat- $k$ locus. Of the 507 plants, 43 plants displayed recombinations for the region between Affx93,173,536 and TGS0486. They were genotyped with two CAPS markers (SNP17 and SNP19) and two SNP markers (SNP6 and SNP13) in the region between Affx-93,173,536 and TGS0486. We then scored these 43 plants for their degree of PL and number of seeds. 


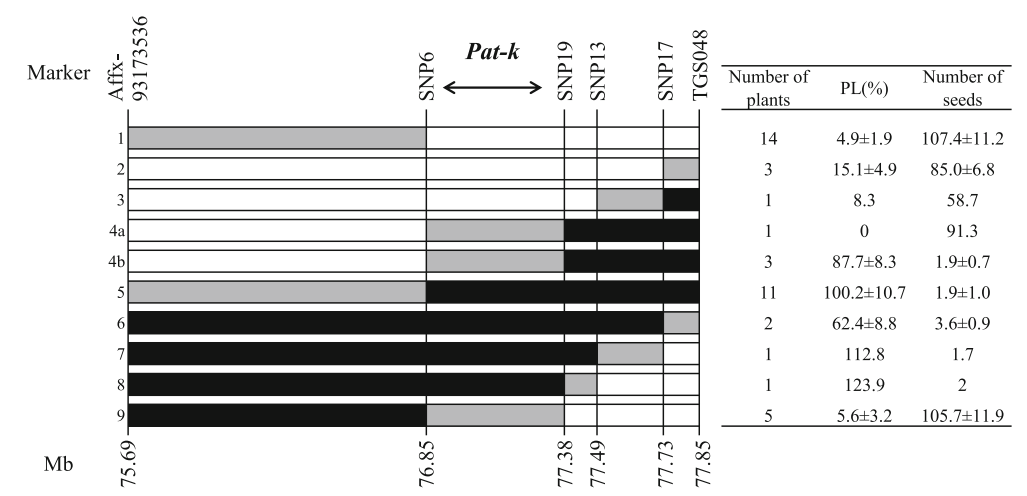

Fig. 4 Fine mapping of Pat-k. Black block stands for homozygous 'MPK-1', white block stands for heterozygous, and gray block stands for interval where crossover took place. Numbers on left side of figure shows classification numbers by the genotype of the corresponding area. Numbers under the bars indicated the position of the above markers on chromosome 1 in Mb (SL2.40). Pat-k was located in the 529 kb region between SNP6 and SNP19

We could divide recombinant plants into nine groups by their genotypes (Fig. 4). Of the nine groups, only Group 4 included both low-scoring PL plants and high-scoring PL plants. Consequently, we concluded that Pat-k located in the region between SNP6 and SNP19 with a physical distance of $529 \mathrm{~kb}$. In addition, the number of seeds of these groups closely corresponded to PL values. The groups in which PL was $>62.4 \%$ (Group $4 \mathrm{~b}$ and $5-8$ in Fig. 4) produced fewer seeds on average $(<3.6$ per plant), whereas the other group, in which PL was $<15.1 \%$ (Group 1-3, 4a, and 9 in Fig. 4), produced more seeds (mean $>58.7$ ) (Fig. 4).

\section{Map-based cloning of Pat-k}

Based on the Sol Genomics Network database [22], there are 60 genes within the $529 \mathrm{~kb}$ region between SNP6 and SNP19. By comparing the sequence of 'MPK-1' and 'Heinz 1706' in this region (using IGV), we could predict that a large DNA fragment was located in a region of Solyc01g093960. By performing PCR analysis, we found an approximate $5 \mathrm{~kb}$ insertion in this region of 'MPK-1' (Additional file 1: Fig. S1). By sequencing the insertion region using primer walking procedures, we identified a $4872 \mathrm{bp}$ insertion at $197 \mathrm{bp}$ downstream of the start codon of Solyc01g093960. The inserted sequence included a 4866 bp segment that was homologous to the LTR retrotransposon CopiaSL_37, which had one SNP at 563 bp downstream of the 5'LTR (Fig. 5). In addition, after comparing the sequence data between 'MPK-1' and 'Heinz 1706' (by IGV and direct sequencing method), we found that there were no polymorphisms in the exon of all 60 genes predicted in the $529 \mathrm{~kb}$ region.

The expression analysis of Solyc01g093960 in ovaries

Our expression analysis showed that transcript levels of Solyc01g093960 were highest at - 1 DAA in the ovaries of 'Louis 60', a non-parthenocarpic tomato cultivar (Fig. 6). The expression level declined considerably in the pollinated ovaries of 'Louis 60' after pollination. On the other hand, the transcript level of Solyc01g093960 was mostly undetectable in the ovary of 'MPK-1' at - 1 DAA (Fig. 7).

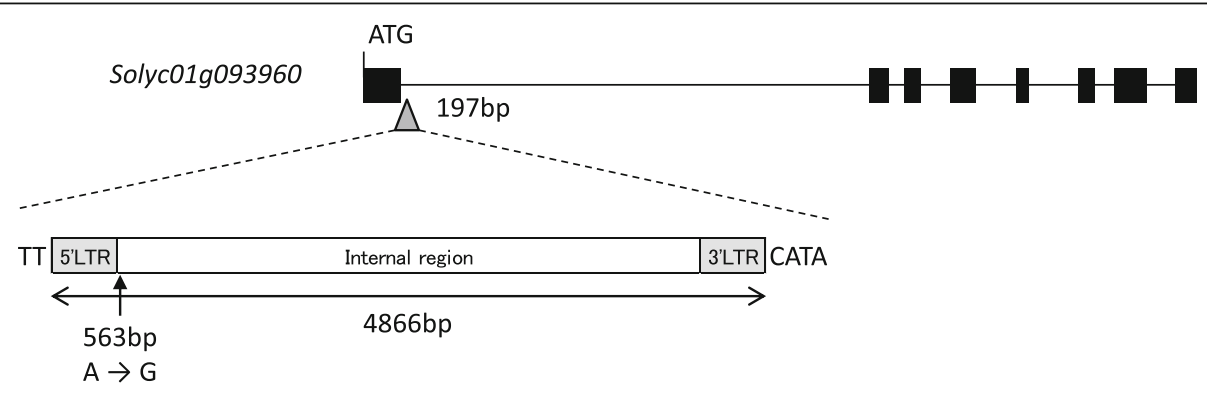

Fig. 5 The structure of Solyc01g093960 of 'Heinz 1706' and the insertion fragment in 'MPK-1'. Black box and black line stand for the exons and introns of Solyc019093960, respectively. The gray triangle indicates the insertion site of CopiaSL_37 retrotransposon. The 2 bp sequence (TT) and 4 bp sequence (CATA) were added to the left and right insertion site, respectively. Arrow indicates a single base substitution from A to $G$ 


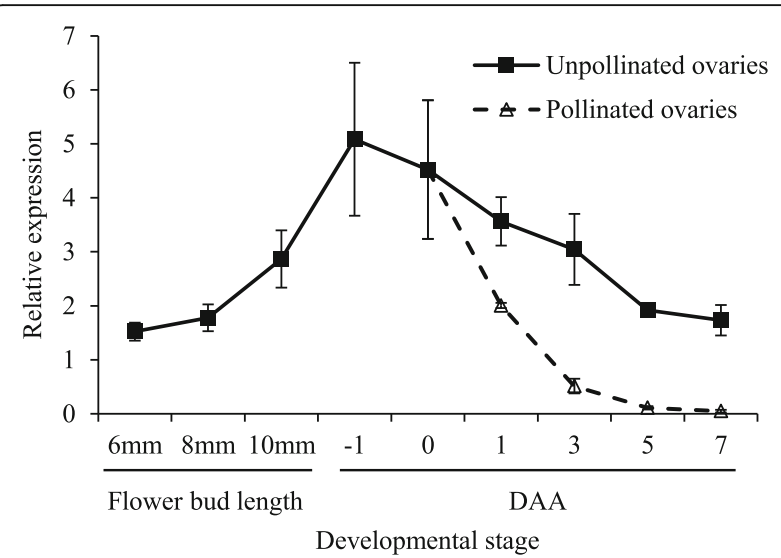

Fig. 6 Transcript levels of Solyc01g093960 in the buds and ovaries of 'Louis 60 '. The unpollinated ovaries and pollinated ovaries were prepared by emasculation at -1 DAA and pollination at 0 DAA. We examined the transcript levels of Solyc01g093960 in the buds of the size 6,8 , and $10 \mathrm{~mm}$ and ovaries at $-1,0,1,3,5$, and 7 DAA. Values indicate means \pm SE $(n=3)$

\section{The relationship between Pat-k and the abnormal} morphology of ovules

To clarify the relationship between Pat-k and ovule structure, we observed ovules in 'Micro-Tom', 'MPK-1, and the $\mathrm{F}_{3}$ population that was homozygous for the 'Micro-Tom' or 'MPK-1' allele at the Pat- $k$ locus. We found abnormal ovules in 'MPK-1' and normal ovules in 'Micro-Tom' (Fig. 8). The normal ovules had micropyles that closed properly. In contrast, the abnormal ovules had micropyles with a cavity. There were no abnormal ovules in the 'Micro-Tom', whereas $40 \%$ were abnormal in 'MPK-1'. There were no abnormal ovules in the $F_{3}$ progeny of 'Micro-Tom' that were homozygous at the

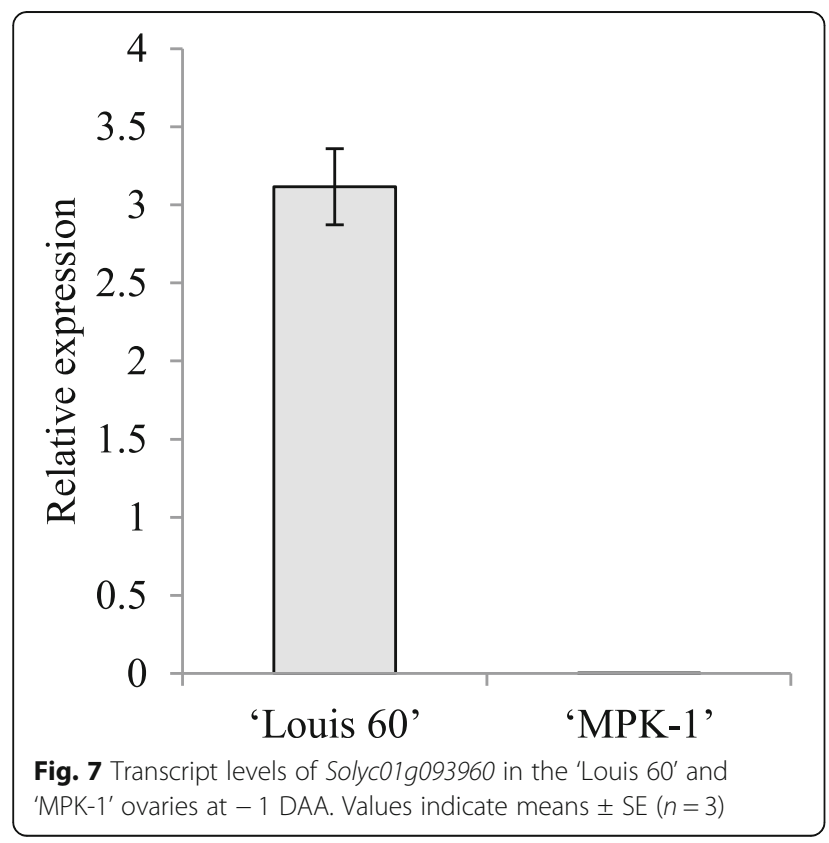

Pat-k locus, whereas $51 \%$ of ovules were abnormal in the $\mathrm{F}_{3}$ progeny of 'MPK-1' that were homozygous at the Pat-k locus.

\section{Discussion}

QTL for parthenocarpy in 'MPK-1'

In this study, we first performed QTL analysis to confirm the factors related to parthenocarpy in 'MPK-1'. Then, we identified only one major QTL, qpat1.1 for PL on chromosome 1 . We had previously reported that parthenocarpy in 'MPK-1' is controlled by a parthenocarpic gene, Pat-k, which is semi-dominant and located on chromosome 1 [1]. We considered qpat1.1 to be Pat-k because they were both detected in the same region of the chromosome 1. However, qpat1.1 appears to be recessive, although we had previously reported that Pat-k was semi-dominant. This discrepancy might be due to the difference in the way we evaluated the parthenocarpy phenotype in the two studies. In the previous report, we evaluated the parthenocarpic phenotype based on the initial development of emasculated ovaries, and separated the phenotypes into three groups: no parthenocarpy (setting fruit, but not growing fruit or dropping flowers), weak parthenocarpy (starting to grow fruit after anthesis), and strong parthenocarpy (starting to grow fruit before or at anthesis) [1]. In contrast, in this study, we evaluated the parthenocarpic phenotype by quantitatively examining the mean final weight of parthenocarpic fruits to that of pollinated fruits. Plants that were heterozygous at the Pat- $k$ locus may promote the initial development of emasculated ovaries to some extent, although the ovaries do not grow as large as pollinated fruits. This suggests that the heterozygous allele on the Pat- $k$ locus affects the initial development of emasculated ovaries, rather than final size of parthenocarpic fruit, which may cause the difference in the effect of genes.

\section{The retrotransposon insertion in SIAGL6 results in parthenocarpy of 'MPK-1'}

In a previous study, Pat- $k$ was mapped at a position close to the SSR marker TGS0486 in chromosome 1 [1]. We conducted fine mapping and map-based cloning to isolate Pat-k. Consequently, we found that the $4866 \mathrm{bp}$ LTR retrotransposon CopiaSL_37 was inserted at the first intron of Solyc01g093960 in the relevant region of chromosome 1 . In addition, there was no polymorphism in the exon of all 60 genes in the region delimited by fine mapping. These results suggest that Pat- $k$ is identical to Solyc01g093960. Our expression analysis showed that the transcript level of Solyc01g093960 is highest in ovaries of 'Louis 60' whose PL was $0 \%$ at -1 DAA. In addition, whereas the transcript levels of Solyc01g093960 in 'Louis 60' and 'Micro-Tom' is 3.11 and 0.79 (data not shown), respectively at - 1 DAA, it is mostly undetectable 

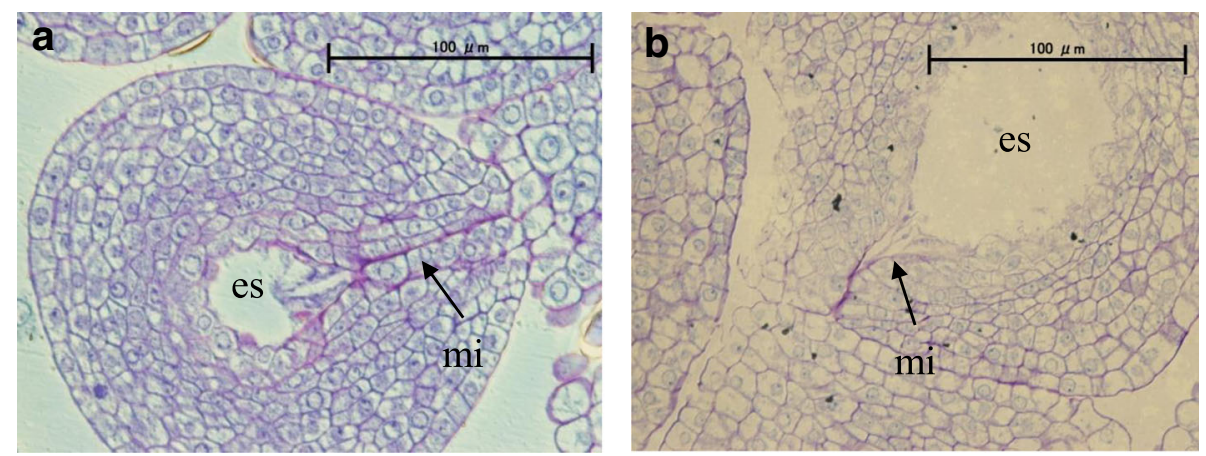

Fig. 8 Morphology of ovules at anthesis. a The ovule of 'Micro-Tom' had a normal micropyle that was tightly closed and looked like a purple line. b the ovule of 'MPK-1' had an abnormal micropyle that had a cavity. es = embryo sac, mi = micropyle

in 'MPK-1' ovaries at that time. Yao [23] reported that the retrotransposon insertion in intron 4 and intron 6 of the MADS-box transcription factor $(M d P I)$ abolished its gene expression, resulting in seedless phenotypes. The source for the high locule number phenotype is a downregulation of the fasciated gene, which encodes a YABBYlike transcription factor, by a large insertion in the first intron [24]. Considering these reports, down-regulation of Solyc01g093960 in 'MPK-1' might also be caused by a retrotransposon insertion in an intron. Very recently, Klap [25] reported that a mutation in Solyc01g093960, which encodes SIAGAMOUS-LIKE 6 (SIAGL6), was responsible for the parthenocarpic phenotype in tomato. In addition, silencing SIAGL6 led to abnormally-fused sepals and light green petals that were smaller-than-normal [26]. Fused sepals were also observed in 'MPK-1' [1]. Taken together, we conclude that the parthenocarpic phenotype of 'MPK-1' is caused by down-regulation of SIAGL6 through a retrotransposon insertion and that the allele of 'MPK-1' in the Pat-k locus originated from a natural mutation.

Hosokawa [7] reported that 'MPK-1' was derived from a cross between a non-parthenocarpic cultivar and a variant from a self-fertilized descendant of 'Severianin' with the parthenocarpic gene, pat-2. Therefore, 'MPK-1' was considered to have pat-2, but in reality, it has Pat-k/ SlAGL6 instead [1, 8]. The parthenocarpic parent of 'MPK-1' has been lost. Therefore, the origin of Pat-k/ SlAGL6 remains a mystery. However, in this study, we showed that the parthenocarpic phenotype of 'MPK-1' is due to the insertion of the retrotransposon, CopiaSL_37. The CopiaSL_37 is reported to be potentially active and autonomous [27], which suggests that the insertion event of CopiaSL_37 may have happened in the parthenocarpic parent of 'MPK- 1 ' or during the selection process, and then 'MPK-1' succeeded it.

\section{QTL for number of seeds in 'MPK-1'}

We identified three QTLs for number of seeds. The QTL, qsn1.1 was located very close to qpat1.1. In addition, PL score and numbers of seeds produced were completely co-segregated in the $\mathrm{F}_{4}$ recombinants. These results suggest that qsn1.1 is identical to Pat-k/SlAGL6. Klap [25] reported that plants that are homozygous for the mutated allele of SIAGL6 set mostly parthenocarpic fruits (and a few seeded fruits), which is consistent with our results. Therefore, we conclude that the inhibition of seed formation in 'MPK-1' was caused by down-regulation of Pat- $k$ / SIAGL6.

Other QTLs for seed production, qsn2.1 and qsn4.1, showed positive additive effects, indicating that an allele from 'Micro-Tom' was responsible for the low number of seeds. 'Micro-Tom', a dwarf cultivar, is regarded as a model cultivar of tomato. The dwarf phenotype of 'Micro-Tom' results from mutations in three major recessive loci: DWARF gene (Solyc02g089160), SELFPRUNING gene (Solyc06g074350), and SlGLK2 gene [28-30]. Of the three genes, DWARF is located within the region of the qsn2.1 locus. The DWARF gene encodes a cytochrome $\mathrm{P} 450$ protein, which functions in the brassinosteroid biosynthesis pathway. Jiang [31] reported that brassinosteroid-deficient and -insensitive mutants have fewer ovules or seeds than the wild type in Arabidopsis. These results suggest that qsn2.1 may be $d$ warf and it reduces the number of seeds through the inhibition of brassinosteroid biosynthesis. It is to be noted that seed production is inhibited by dwarf in 'Micro-Tom'.

We grouped $F_{2}$ progeny according to the genotypes of qsn4.1 and then compared the average weight of pollinated fruit among genotypes. Our results show that the average weight of pollinated fruit is less in plants with the 'Micro-Tom' homozygous allele than in plants with the heterozygous allele and the 'MPK-1' homozygous allele. Actually, the QTL for pollinated fruit weight was detected on chromosome 4 in the $F_{2}$ population (data not shown). These results suggest that qsn4.1 is responsible for reduced fruit size, which also causes a reduction in the number of seeds. 


\section{The relationship between Pat-k/SIAGL6 and abnormal ovule}

In eudicots, flowers consist of sepals, petals, stamens, and pistils. Based on studies in two eudicot plants, Arabidopsis thaliana and Antirrhinum majus, an ABC model was established that explains how three classes of genes jointly specify floral organ identity [32]: A class, $\mathrm{A}$ and $\mathrm{B}$ class, $\mathrm{A}$ and $\mathrm{C}$ class, and $\mathrm{C}$ class determine sepals, petals, stamens, and carpels, respectively. Later, the model was expanded by finding genes of D and E class. D class specifies the ovule [33, 34], whereas $\mathrm{E}$ class genes determine the identity of all flower organs and regulates floral meristem determinacy [35-37]. The AGL6 subfamily of genes belongs to $\mathrm{E}$ class, and they function in flower development, such as the SEPALLATA genes, which are well characterized E class genes [38].

$\mathrm{Yu}$ [26] reported that SlAGL6 is a potential E-function gene because its expression profile was similar to Petunia AGL6, lineage member. Pattison [39] reported that the transcript level of SIAGL6 in the ovules is higher than in the other tissues of the ovary. High expression levels of AGL6-like genes in ovules seem to be well conserved among some species [40-43]. Rijpkema [42] suggested that PhAGL6 plays a role during ovule development, based on its expression pattern. The osmads6 mutant, which is a mutation of OsMADS6 (AGL6-like genes), has defective ovules, which leads to fewer seed set [41]. In our study, we observed ovules with abnormal micropyles only in progenies homozygous for the 'MPK1 ' allele at the Pat-k/SlAGL6 locus, which suggests that Pat-k/SlAGL6 is involved with ovule formation in tomato and that its down-regulation causes abnormal ovules. In addition, the percentage of germination of hybrid seeds between 'MPK-1' and 'Louis 60' was low and the internal structure of the seeds was abnormal [8]. This suggests that abnormal ovules inhibit normal seed formation. It was reported that SlAGL6 is a single, recessives gene for parthenocarpy and there are no adverse effects on fruit weight or shape or on vegetative traits in SlAGL6-mutated lines [25]. These traits indicate that Pat-k/SlAGL6 should be a desirable gene for breeding parthenocarpic cultivars. However, in our study, the down-regulation of Pat-k/SlAGL6 not only exhibits stable parthenocarpy, but also inhibits seed formation via abnormal ovule formation. Although the treatment of gibberellin biosynthesis inhibitor or inhibitor of auxin action increases the number of seeds in 'Renaissance', a parthenocarpic cultivar with pat-2, [44, 45], they have no effect on seed production in 'MPK-1' (unpublished data). This result shows that it is difficult to increase the number of seeds in a SlAGL6-mutated line using a chemical that affects the biosynthesis or signaling of plant hormones. However, Klap [25] reported that environmental conditions and genetic background together affect seed production, indicating that it is possible to increase the number of seeds by finding good cross combination or by improving field conditions for seed production.

\section{Conclusion}

In this study, we identified one QTL for PL and three QTLs for seed production in tomato. Fine mapping and a whole genome re-sequencing of 'MPK-1' identified that Pat-k was identical to SlAGL6. The insertion of retrotransposon in the first intron of SlAGL6 downregulates the transcript level of SIAGL6 in 'MPK-1' ovaries, which causes parthenocarpy and low seed set in 'MPK-1'. Moreover, all $F_{3}$ progenies homozygous for the 'MPK-1' allele of the Pat-k/SlAGL6 locus had ovules with abnormal micropyles, which indicates that Pat-k/SlAGL6 is involved with ovule formation and that its downregulation causes abnormal ovule formation and low seed set.

\section{Additional file}

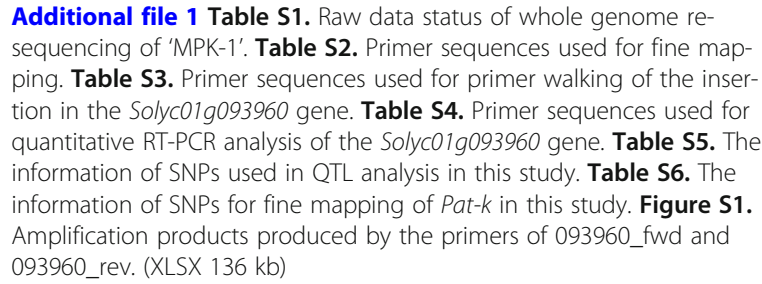

\section{Abbreviations}

CAPS: Cleaved amplified polymorphic sequences; DAA: Days after anthesis; IGV: Integrative genomics viewer; LOD: Logarithm of odds; PL: Parthenocarpy level; QTL: Quantitative trait locus; SIAGL6: SIAGAMOUS-LIKE 6; SNP: Single nucleotide polymorphism

\section{Funding}

This work was supported by a Grant-in-Aid for Young Scientists (B) [15 K18639] from the Japan Society for the Promotion of Science.

\section{Availability of data and materials}

All data generated or analysed during this study are included in this published article and its supplementary information files, and the raw data of resequencing of 'MPK-1' has been submitted to DDBJ (Accession: DRA006668).

\section{Authors' contributions}

RT conceived and designed the experiments. RT, TN, HF, HS, and TH performed QTL analysis, fine mapping or map-based cloning. KK, TN, and AK supervised the study and contributed to revising the manuscript. All authors read and approved the final manuscript.

Ethics approval and consent to participate Not applicable

Competing interests

The authors declare that they have no competing interests. 


\section{Publisher's Note}

Springer Nature remains neutral with regard to jurisdictional claims in published maps and institutional affiliations.

\begin{abstract}
Author details
'Graduate School of Agriculture, Kyoto University, Kizugawa 619-0218, Japan. ${ }^{2}$ NARO Institute of Vegetable and Floriculture Science, Tsu 514-2392, Japan.

${ }^{3}$ NARO Institute of Vegetable and Tea Science, Tsu 514-2392, Japan.

${ }^{4}$ Graduate School of Agriculture, Ehime University, Matsuyama 790-8566, Japan. ${ }^{5}$ Present Address: Tropical Agriculture Research Front Japan International Research Center Agricultural Sciences, 1091-1, Kawarabaru, Aza Maezato, Ishigaki, Okinawa 907-0002, Japan.
\end{abstract}

\section{Received: 19 November 2017 Accepted: 10 April 2018} Published online: 27 April 2018

\section{References}

1. Takisawa R, Maruyama T, Nakazaki T, Kataoka K, Saito H, Koeda S, et al Parthenocarpy in the tomato (Solanum lycopersicum L.) cultivar 'MPK-1' is controlled by a novel parthenocarpic gene. Hort J. 2017;86:487-92.

2. George WL, Scott JW, Splittstoesser WE. Parthenocarpy in tomato. Hort Rev. 1984;6:65-84.

3. Picken AJF. A review of pollination and fruit set in the tomato (Lycopersicon esculentum mill.). J Hortic Sci. 1984;59:1-13.

4. Gorguet B, Eggink PM, Ocana J, Tiwari A, Schipper D, Finkers R, Visser RG, van Heusden AW. Mapping and characterization of novel parthenocarpy QTLs in tomato. Theor Appl Genet. 2008;116:755-67.

5. Gorguet B, van Heusden AW, Lindhout P. Parthenocarpic fruit development in tomato. Plant Biol. 2005;7:131-9.

6. Nunome T, Honda I, Ohyama A, Fukuoka H, Yamaguchi H, Miyatake K. Parthenocarpy regulation gene and use thereof. Patent WO. 2013; 2014021398:A1.

7. Hosokawa M, Matsumura S, Hayashi T, Yazawa S. Plant regeneration of stable parthenocarpic tomato cultivars from shoot apical meristems attached to root tips. Jpn J Taste Smell Res. 2004:11:61-8.

8. Takisawa R, Kataoka K, Kitajima A. Inhibition of seed formation by anomalous ovule in 'Kyo-temari', a parthenocarpic tomato (Solanum lycopersicum L.) cultivar. J Soc Hort Sci. 2012;81:251-6.

9. Kataoka K, Okita H, Uemachi A, Yazawa S. A pseudoembryo highly stainable with toluidine blue $\mathrm{O}$ may induce fruit growth of parthenocarpic tomato. Acta Hortic. 2004;637:213-21.

10. Mazzucato A, Taddei AR, Soressi GP. The parthenocarpic fruit (pat) mutant of tomato (Lycopersicon esculentum mill.) sets seedless fruits and has aberrant anther and ovule development. Development. 1998;125:107-14.

11. Ampomah-Dwamena C, Morris BA, Sutherland P, Veit B, Yao JL. Downregulation of TM29, a tomato SEPALLATA homolog, causes parthenocarpic fruit development and floral reversion. Plant Physiol. 2002;130:605-17.

12. de Martino G, Pan I, Emmanuel E, Levy A, Irish VF. Functional analyses of two tomato APETALA3 genes demonstrate diversification in their roles in regulating floral development. Plant Cell. 2006;18:1833-45.

13. Daminato $M$, Masiero $S$, Resentini F, Lovisetto A, Casadoro G. Characterization of TM8, a MADS-box gene expressed in tomato flowers. BMC Plant Biol. 2014;14:319.

14. Ocarez N, Mejia N. Suppression of the D-class MADS-box AGL11 gene triggers seedlessness in fleshy fruits. Plant Cell Rep. 2016;35:239-54.

15. Yamamoto $E$, Matsunaga $H$, Onogi A, Kajiya-Kanegae $H$, Minamikawa M, Suzuki A, Shirasawa K, Hirakawa H, Nunome T, Yamaguchi H, Miyatake K, Ohyama A, Iwata H, Fukuoka H. A simulation-based breeding design that uses whole-genome prediction in tomato. Sci Rep. 2016:6:19454.

16. Wang S, Basten CJ, Zeng ZB. Windows QTL cartographer version 2.5. Raleigh: NCSU Statistical Genetics; 2007.

17. Nagasaki H, Mochizuki T, Kodama Y, Saruhashi S, Morizaki S, Sugawara H, Ohyanagi H, Kurata N, Okubo K, Takagi T, Kaminuma E, Nakamura Y. DDBJ read annotation pipeline: a cloud computing-based pipeline for highthroughput analysis of next-generation sequencing data. DNA Res. 2013;20:383-90

18. Robinson JT. Integrative genomics viewer. Nat Biotechnol. 2011;29:24-6.

19. Kudo T, Kobayashi M, Terashima S, Katayama M, Ozaki S, Kanno M, Saito M, Yokoyama K, Ohyanagi H, Aoki K, Kubo Y, Yano K. TOMATOMICS: a web database for integrated omics information in tomato. Plant Cell Physiol. 2017;58:e8.
20. Untergasser A, Nijveen H, Rao X, Bisseling T, Geurts R, Leunissen JAM. Primer3Plus, an enhanced web interface to Primer3. Nucleic Acids Res. 2007;35:W71-4

21. Zouine M, Fu Y, Chateigner-Boutin AL, Mila I, Frasse P, Wang H, Audran C, Roustan JP, Bouzayen M. Characterization of the tomato ARF gene family uncovers a multi-levels post-transcriptional regulation including alternative splicing. PLoS One. 2014;9:e84203.

22. Fernandez-Pozo N, Menda N, Edwards JD, Saha S, Tecle IY, Strickler SR, Bombarely A, Fisher-York T, Pujar A, Foerster H, Yan A, Mueller LA. The sol genomics network (SGN) — from genotype to phenotype to breeding. Nucleic Acids Res. 2015;43:D1036-41.

23. Yao J, Dong Y, Morris BA. Parthenocarpic apple fruit production conferred by transposon insertion mutations in a MADS-box transcription factor. Proc Natl Acad Sci U S A. 2001;98:1306-11

24. Cong B, Barrero LS, Tanksley SD. Regulatory change in YABBY-like transcription factor led to evolution of extreme fruit size during tomato domestication. Nat Genet. 2008:40:800-4.

25. Klap C, Yeshayahou E, Bolger AM, Arazi T, Gupta SK, Shabtai S, Usadel B, Salts $Y$, Barg R. Tomato facultative parthenocarpy results from SIAGAMOUSLIKE 6 loss of function. Plant Biotechnol J. 2017;15:634-47.

26. Yu X, Chen G, Guo X, Lu Y, Zhang J, Hu J, Tian S, Hu Z. Silencing SIAGL6, a tomato AGAMOUS-LIKE6 lineage gene, generates fused sepal and green petal. Plant Cell Rep. 2017;36:959-69.

27. Paz RC, Kozaczek ME, Andino NP, Sanchez-Puerta MV. Diversity and distribution of potentially active Copia and gypsy LTR retroelement families inhabiting the genome of Solanum lycopersicum cv. Heinz. 11th international congress of plant molecular biology. 2015.

28. Pnueli L, Carmel-Goren L, Hareven D, Gutfinger T, Alvarez J, Ganal M, Zamir D, Lifschitz E. The SELF-PRUNING gene of tomato regulates vegetative to reproductive switching of sympodial meristems and is the ortholog of CEN and TFL 1. Development. 1998;125:1979-89.

29. Marti E, Gisbert C, Bishop GJ, Dixon MS, Garcia-Martinez JL. Genetic and physiological characterization of tomato cV. Micro-Tom J Exp Bot. 2006; 57:2037-47

30. Powell AL, Nguyen CV, Hill T, Cheng KL, Figueroa-Balderas R, Aktas $H$, Ashrafi H, Pons C, Fernandez-Munoz R, Vicente A, Lopez-Baltazar J, Barry CS, Liu Y, Chetelat R, Granell A, Van Deynze A, Giovannoni JJ, Bennett AB. Uniform ripening encodes a Golden 2-like transcription factor regulating tomato fruit chloroplast development. Science. 2012;336:1711-5.

31. Jiang WB, Huang HY, Hu YW, Zhu SW, Wang ZY, Lin WH. Brassinosteroid regulates seed size and shape in Arabidopsis. Plant Physiol. 2013;162:1965-77.

32. Coen ES, Meyerowitz EM. The war of the whorls: genetic interactions controlling flower development. Nature. 1991;353:31-7.

33. Angenent GC, Franken J, Busscher M, van Dijken A, van Went JL, Dons $\mathrm{HJ}$, van Tunen AJ. A novel class of MADS box genes is involved in ovule development in petunia. Plant Cell. 1995;7:1569-82.

34. Colombo L, Franken J, Koetje E, van Went J, Dons HJ, Angenent GC, van Tunen AJ. The petunia MADS box gene FBP11 determines ovule identity. Plant Cell. 1995;7:1859-68.

35. Ditta G, Pinyopich A, Robles P, Pelaz S, Yanofsky MF. The SEP4 gene of Arabidopsis thaliana functions in floral organ and meristem identity. Curr Biol. 2004;14:1935-40.

36. Pelaz S, Ditta GS, Baumann E, Wisman E, Yanofsky MF. B and C floral organ identity functions require SEPALLATA MADS-box genes. Nature. 2000:405:200-3.

37. Theissen G. Development of floral organ identity: stories from the MADS house. Curr Opin Plant Biol. 2001;4:75-85.

38. Dreni L, Zhang D. Flower development: the evolutionary history and functions of the AGL6 subfamily MADS-box genes. J Exp Bot. 2016;67:1625-38.

39. Pattison RJ, Csukasi F, Zheng Y, Fei Z, van der Knaap E, Catala C. Comprehensive tissue-specific transcriptome analysis reveals distinct regulatory programs during early tomato fruit development. Plant Physiol. 2015;168:1684-701.

40. Favaro R, Immink RG, Ferioli V, Bernasconi B, Byzova M, Angenent GC, Kater M, Colombo L. Ovule-specific MADS-box proteins have conserved protein-protein interactions in monocot and dicot plants. Mol Gen Genomics. 2002:268:152-9.

41. Li H, Liang W, Jia R, Yin C, Zong J, Kong H, Zhang D. The AGL6-like gene OsMADS6 regulates floral organ and meristem identities in rice. Cell Res. 2010;20:299-313. 
42. Rijpkema AS, Zethof J, Gerats T, Vandenbussche M. The petunia AGL6 gene has a SEPALLATA-like function in floral patterning. Plant J. 2009;60:1-9.

43. Schauer SE, Schluter PM, Baskar R, Gheyselinck J, Bolanos A, Curtis MD, Grossniklaus U. Intronic regulatory elements determine the divergent expression patterns of AGAMOUS-LIKE6 subfamily members in Arabidopsis. Plant J. 2009;59:987-1000.

44. Johkan M, Chiba T, Mitsukuri K, Yamasaki S, Tanaka H, Mishiba K, Morikawa T, Oda $\mathrm{M}$, Yamamoto $\mathrm{C}$, Ohkawa $\mathrm{H}$. Seed production enhanced by antiauxin in the pat-2 parthenocarpic tomato mutant. J Am Soc Hortic Sci. 2010;135:3-8.

45. Ohkawa H, Sugahara S, Oda M. Seed formation promoted by paclobutrazol, a gibberellin biosynthesis inhibitor, in pat-2 parthenocarpic tomatoes. J Japan Soc Hort Sci. 2012;81:177-83.

Ready to submit your research? Choose BMC and benefit from:

- fast, convenient online submission

- thorough peer review by experienced researchers in your field

- rapid publication on acceptance

- support for research data, including large and complex data types

- gold Open Access which fosters wider collaboration and increased citations

- maximum visibility for your research: over $100 \mathrm{M}$ website views per year

At BMC, research is always in progress.

Learn more biomedcentral.com/submissions 